\title{
Sarcoma sinovial insidioso de osso em um paciente com artrite reumatoide
}

\section{Insidious Synovial Sarcoma of Bone in a Patient with Rheumatoid Arthritis}

\author{
Juan Carlos Reyes Villarreal ${ }^{10}$ Luis Francisco Pineda-Galindo ${ }^{10}$ Olga Vera-Lastra1( \\ Elizabeth Natalia Quispe-Susara ${ }^{20}$ Alberto Ordinola Navarro ${ }^{10}$
}

1 Departamento de Medicina Interna, Hospital de Especialidades "Dr. Antonio Fraga Mouret,"Centro Médico Nacional La Raza del Instituto Mexicano del Seguro Social, Cidade do México, México

2 Departamento de Patologia, Hospital de Especialidades "Dr. Antonio Fraga Mouret,"Centro Médico Nacional La Raza del Instituto

Mexicano del Seguro Social, Cidade do México, México
Endereço para correspondência Alberto Ordinola Navarro, MD, Department of Internal Medicine, Hospital de Especialidades “Dr. Antonio Fraga Mouret, Centro Médico Nacional La Raza del Instituto Mexicano del Seguro Social, Calle Seris y Zaachila, La Raza, 02990 Azcapotzalco, Mexico City, Mexico (e-mail: albertoordinolamd@gmail.com).

Rev Bras Ortop

\section{Resumo}

Palavras-chave

- sarcoma sinovial

- neoplasias de tecidos moles

- artrite reumatoide

Abstract

Keywords

- sarcoma, synovial

- soft tissue neoplasms

- arthritis, rheumatoid
Sarcoma sinovial é uma rara malignidade de origem mesenquimal; a abordagem diagnóstica geralmente começa documentando um tumor de tecido mole; no entanto, resulta em um diagnóstico desafiador quando é mais profundo, de pequeno porte ou primário do osso. O presente relato descreve um paciente que apresentou dor insidiosa no quadril atribuída a artrite reumatoide, com desfecho fatal devido a doenças de base e complicações cirúrgicas.

A subestimação da dor no quadril, principalmente quando não há massa palpável, pode atrasar o diagnóstico.

Synovial sarcoma is a rare malignity of mesenchymal origin; the diagnostic approach usually begins by documenting a soft tissue tumor; however, it results in a challenging diagnosis when it is more profound, of small size, or primary from the bone.

The present report describes a patient who presented insidious onset hip pain attributed to rheumatoid arthritis, with a fatal outcome due to baseline disease and surgery complications.

The underestimation of hip pain, mainly when there is no palpable mass, may delay the diagnosis.

$\overline{\text { Trabalho }}$ desenvolvido no Hospital de Especialidades Dr. Antonio Fraga Mouret, Centro Médico Nacional La Raza del Instituto Mexicano del Seguro Social, Cidade do México, México.

recebido

21 de Maio de 2021

aceito

02 de Setembro de 2021
DOI https://doi.org/

10.1055/s-0041-1739172. ISSN 0102-3616. (c) 2021. Sociedade Brasileira de Ortopedia e Traumatologia. All rights reserved.

This is an open access article published by Thieme under the terms of the Creative Commons Attribution-NonDerivative-NonCommercial-License, permitting copying and reproduction so long as the original work is given appropriate credit. Contents may not be used for commercial purposes, or adapted, remixed, transformed or built upon. (https://creativecommons.org/ licenses/by-nc-nd/4.0/)

Thieme Revinter Publicações Ltda., Rua do Matoso 170, Rio de Janeiro, RJ, CEP 20270-135, Brazil 


\section{Introdução}

Os sarcomas sinoviais (SSs) são uma rara neoplasia mesenquimal com capacidades de dupla diferenciação; uma massa de tecido mole periarticular é a apresentação mais comum; no entanto, eles podem surgir de qualquer local. ${ }^{1,2} \mathrm{~A}$ subestimação da dor no quadril, principalmente quando não há massa palpável ou um tumor de tecido mole em estudos de imagem, pode atrasar o diagnóstico.

\section{Relatório do Caso}

Um homem de 67 anos com 20 anos de história de artrite reumatoide (AR) começou com dor no quadril; ele foi avaliado por diferentes departamentos, sendo os sintomas atribuídos a AR e indicando apenas tratamento sintomático.

Um ano depois, ele foi encaminhado ao nosso hospital devido à persistência de dor e edema dos membros inferiores. Foi realizada tomografia na internação, relatando lesão osteolítica no pescoço e na cabeça do fêmur (-Fig. 1A). O paciente desenvolveu trombose venosa profunda, a qual evoluiu para necrose do dedão do pé esquerdo; testes laboratoriais significativos incluíram crioglobulinas soropositivas (monoclonal e igM monoclonal) elevados, fator reumatoide elevado e hipocomplementaemia (-Fig. 1B). Ele foi para a sala de cirurgia, onde a cabeça do fêmur direito foi resseccionada, sendo colocada uma mega próstese proximal do fêmur (-Fig. 1C). Durante o pós-operatório, o paciente desenvolveu uma infecção no sítio cirúrgico; ele foi tratado com antibióticos, limpeza de ferida e debridamento. Diagnóstico histológico revelado: células epiteliais e fusos positivas para citoqueratina 7, BCL2 e CD99. Estudos moleculares com expressão de proteínas de fusão translocação $(\mathrm{X} ; 18)$ (p11.2; q11.2) e expressão de proteínas de fusão SS18-SSX1 corroboraram o diagnóstico de SS bifásico. No entanto, ele se complicou com doença cerebrovascular e tromboembolismo pulmonar e morreu.

\section{Discussão}

O presente relatório descreve um paciente que apresentou dor insidiosa no quadril atribuída a AR, com desfecho fatal devido a doenças de base e complicações cirúrgicas.

O SS é uma malignidade rara de origem mesenquimal que compreende $\sim 10 \%$ dos sarcomas de tecido mole. Pode apresentar-se em qualquer local anatômico, mas decorrente de tecido mole é a apresentação mais comum. ${ }^{1}$ O SS como um tumor ósseo primário é relativamente raro e é mais frequente em pacientes adultos jovens. ${ }^{2}$

O SS foi inicialmente descrito como uma neoplasia bifásica composta por componentes epiteliais e células de fuso; no entanto, foram identificadas variantes histológicas como monofásica, bifásica e pouco diferenciada. ${ }^{1,2}$ De acordo com a série relatada, os principais sintomas são dor neuropática e local, déficit motor e massa palpável; em nosso paciente, a sintomatologia insidiosa e a história da doença reumática atrasaram o diagnóstico. ${ }^{3}$

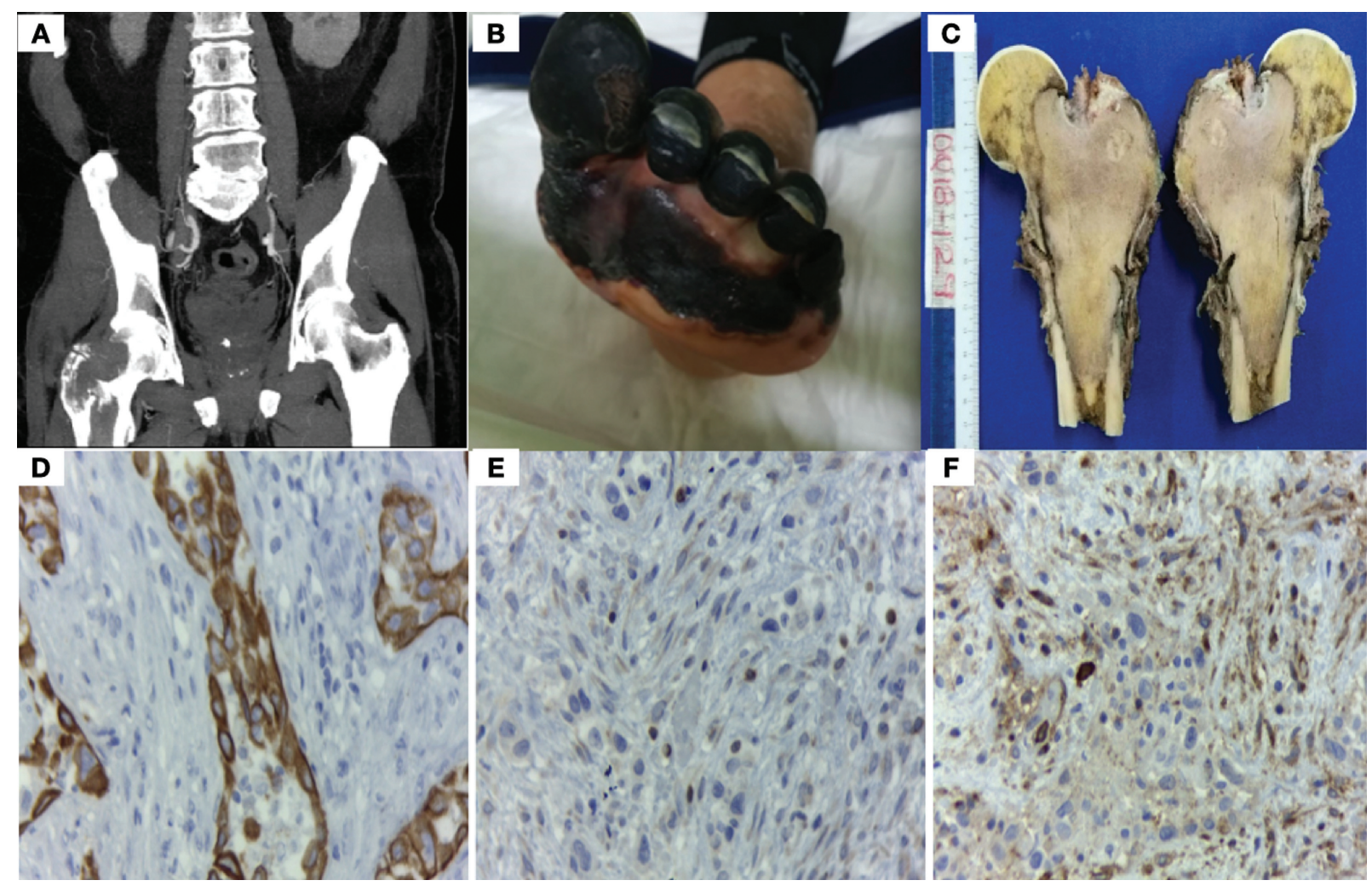

Fig. 1 (A) Tomografia computadorizada mostrando lesão osteolítica no pescoço e na cabeça do fêmur. (B) Trombose venosa profunda com necrose distal. (C) Pescoço e cabeça femorais direitas mostrando infiltração intraóssea. (D-F) Imunohistoquímica. A identificação de CK7 (D), BCL-2 (E) e CD99 (F) foi a chave para suspeitar do diagnóstico de sarcoma sinovial. 
A abordagem diagnóstica geralmente começa documentando um tumor de tecido mole; quando é superficial, é fácil identificá-lo; no entanto, quando é mais profundo, de pequeno porte ou primário do osso, estudos de imagem mostrando hemorragia interna, calcificação ou lesões osteolíticas podem nos ajudar a guiar nossa suspeita diagnóstica. ${ }^{2}$ No nosso paciente, foi realizada a tomografia computadorizada, na qual não foi encontrado tumor; no entanto, foi relatada uma lesão osteolítica da cabeça femoral direita, o que levou à suspeita de tumor ósseo.

A imunohistoquímica é essencial para suspeitar do diagnóstico. Neste paciente, CK7, CD99 e BCL2 capacitaram a suspeita do diagnóstico e do tumor ser classificado como bifásico, uma vez que CK7 é encontrado em células epiteliais e CD99 juntamente com BCL2 são encontrados em células de fuso (Fig. 0.1 D-F). ${ }^{4}$

O SS tem uma translocação patognomônica entre os cromossomos X e 18, t (X;18) (p11.2;q11.2), traduzindose em várias expressões diferentes de proteínas de fusão SS18:SSx; sendo SS18-SSX1 e SS18:SSX2 os mais comuns. Após a imunohistoquímica, foi possível corroborar o diagnóstico demonstrando a expressão de translocação e proteínas de fusão; a fusão é detectável em $>95 \%$ dos casos, sendo uma ferramenta-chave para confirmar o diagnóstico. $^{1,4}$

A doença metastática está presente em $24 \%$ dos pacientes no momento do diagnóstico e o prognóstico para pacientes sem metástase é favorável. No entanto, a metástase ocorre em 50 a 70\% dos casos, e a maioria se desenvolve nos pulmões, seguida por osso e fígado. O tratamento padrão é a ressecção cirúrgica para SSs localizadas com a consideração do uso de radiação adjuvante e ou terapia anticâncer sistêmica. No entanto, não há uma abordagem padrão para o uso da terapia sistêmica. Quando prescritas, antraciclina mais ifosfamida são geralmente a terapia de primeira linha. No entanto, futuros ensaios clínicos definiriam um tratamento adequado para esta doença. ${ }^{5} \mathrm{O}$ conhecimento da doença pode ajudar a orientar a imunohistoquímica, corroborando o diagnóstico e iniciando uma terapia individualizada que leva a melhores resultados.

\section{Suporte Financeiro}

A presente pesquisa não recebeu nenhuma subvenção específica de agências de fomentação nos setores público, comercial ou sem fins lucrativos.

\section{Conflito de Interesses}

Os autores não têm conflito de interesses a declarar.

\section{Confirmações}

Agradecemos à família do paciente por ter concedido permissão para publicar esta informação. O consentimento informado foi obtido do paciente.

\section{Referências}

1 Stacchiotti S, Van Tine BA. Synovial Sarcoma: Current Concepts and Future Perspectives. J Clin Oncol 2018;36(02):180-187

2 Caracciolo JT, Henderson-Jackson E, Binitie O. Synovial sarcoma of bone: Sarcoma typically of soft tissues presenting as a primary bone tumor. Radiol Case Rep 2018;14(02):204-207

3 Burks SS, Puffer RC, Cajigas I, et al. Synovial Sarcoma of the NerveClinical and Pathological Features: Case Series and Systematic Review. Neurosurgery 2019;85(06):E975-E991

4 Jones KB, Barrott JJ, Xie M, et al. The impact of chromosomal translocation locus and fusion oncogene coding sequence in synovial sarcomagenesis. Oncogene 2016;35(38):5021-5032

5 Riedel RF, Jones RL, Italiano A, et al. Systemic Anti-Cancer Therapy in Synovial Sarcoma: A Systematic Review. Cancers (Basel) 2018; 10(11):417 